\title{
MÉTODO GEOMORFOMÉTRICO PARA MAPEAMENTO DE LEQUES ALUVIAIS
}

Ricardo Michael Pinheiro Silveira ${ }^{1}$ Claudinei Taborda da Silveira ${ }^{2}$

Resumo: No âmbito da análise digital do relevo, este trabalho apresenta a concepção e aplicação de um método para a identificação de leques aluviais com a parametrização e combinação de atributos geomorfométricos calculados a partir de um modelo digital do terreno (MDT), cuja área de estudo compreende o estado do Paraná (Brasil). Na classificação orientada a objeto, os leques aluviais foram tratados como pontos planos localizados na interseção de segmentos lineares, definidos pela área de contribuição, que possuem grande amplitude altimétrica e de declividade. Os resultados evidenciaram que o mapeamento dos leques aluviais foi representativo em distintos contextos geomorfológicos, o que ressalta sua aplicabilidade.

Palavras-chave: Modelo digital do terreno. Geomorfometria. Cartografia geomorfológica. Análise digital do terreno.

\section{GEOMORPHOMETRIC METHOD FOR ALLUVIAL FAN MAPPING}

Abstract: In the context of digital terrain analysis, this study presents the conception and application of a method for the identification of alluvial fans with the parameterization and combination of geomorphometric attributes calculated from a digital terrain model (DTM), whose area of study is the state of Paraná (Brazil). In object-oriented classification, alluvial fans were treated as flat points located at the intersection of linear segments, defined by the contributing area, which have high altimetric (relief) and slope amplitude. The results showed that the alluvial fan mapping was representative in different geomorphological contexts, which highlights its applicability.

Keywords: Digital terrain model. Gemophometry. Geomorphological mapping. Digital terrain analysis.

\section{MÉTODO GEOMORFOMÉTRICO PARA IDENTIFICACIÓN DE ABANICOS ALUVIALES}

Resumen: En la perspectiva del análisis digital del terreno, este trabajo presenta la concepción y aplicación de un método para la identificación de abanicos aluviales con la parametrización y combinación de atributos geomorfométricos calculados con base en un modelo digital del terreno (MDT), cuyo recorte geográfico es el estado del Paraná (Brasil). En la clasificación orientada a objeto, los abanicos aluviales fueron tratados como pontos planos ubicados en la intersección de segmentos lineares, definidos por el área de contribución, que tiene una alta amplitud altimétrica y de pendiente. Los resultados evidenciaron que el mapeo de los abanicos aluviales fue representativo en distintos contextos geomorfológicos, lo que señala su aplicabilidad.

\footnotetext{
1 Universidade Federal do Paraná, PPGGEO, Curitiba, Brasil, ricardomichaelps@gmail.com, http://orcid.org/0000-0002-5664-7079

2 Universidade Federal do Paraná, Departamento de Geografia, Curitiba, Brasil, claudineits@ufpr.br, https://orcid.org/0000-0001-6289-6306
} 
Palabras clave: Modelo digital del terreno. Geomorfometría. Cartografía geomorfológica. Análisis digital del terreno.

\section{Introdução}

A geomorfometria, definida como a ciência da análise quantitativa da superfície terrestre (PIKE, 2000), tem proporcionado um arcabouço teóricometodológico de destaque para aplicações direcionadas ao estudo da dinâmica e à cartografia do relevo (LI et al., 2005; SEIJMONSBERGEN et al., 2011). Isso se deve, sobretudo, à crescente disponibilidade de modelos digitais do terreno (MDT), que na geomorfometria comumente configuram-se, segundo Hengl e Reuter (2009) e Evans (2012), na estrutura de matrizes de pontos, em coordenadas cartesianas, com atribuição de valores de elevação (altitude). Os parâmetros obtidos a partir dos MDTs constituem descritores que representam mensurações quantitativas do relevo (WILSON e GALLANT, 2000), tais como declividade, curvatura e índices topográficos, também denominados de atributos geomorfométricos (SCHMIDT e DIKAU, 1999).

Considerando a caracterização de Evans (1972), a geomorfometria pode ser distinguida entre geral e específica. Conforme Macmillan e Shary (2009), a geomorfometria geral, sendo empregada para descrever a superfície contínua (parâmetros), proporciona a base para a comparação quantitativa de paisagens distintas, além de auxiliar na adaptação de métodos de análise da superfície utilizados em campos afins à geomorfologia. Já a geomorfometria específica pode ser utilizada para descrever formas de relevo discretas (objetos), como vulcões, dunas, montanhas e envolve decisões arbitrárias e subjetivas nas etapas prévias, de conceituação, e posteriores, de quantificação. Evans (2012) salienta que a geomorfometria específica também tem a função de analisar as características geométricas e topológicas das formas de relevo.

Nesse sentido, a geomorfometria considera a relação entre objetos geomorfológicos (principalmente formas de relevo) e os parâmetros numéricos usados para descrevê-los (BOLONGARO-CREVENNA et al., 2005), na qual a extração de assinaturas para a representação de objetos geomorfológicos (PIKE, 1988) desponta como um dos objetivos principais. Apesar das potencialidades, Wilson (2012) pondera que tanto os valores dos parâmetros quanto as características dos objetos variam considerando diversos fatores, como o modelo 
matemático pelo qual são calculados os atributos, o tamanho da janela móvel para os cálculos de vizinhança e a resolução espacial do MDT (tamanho das células).

Dentre as formas de relevo que tradicionalmente compõem mapas geomorfológicos, os leques aluviais se caracterizam como elemento de destaque. Embora seja um objeto morfográfico, vincula-se, também, às características morfodinâmicas (hidrológicas) e morfogenéticas. Os leques aluviais são feições sedimentares cônicas, cujo depósito ocorre em locais onde a capacidade de transporte dos canais diminui abruptamente, como nos sopés de montanhas (HARVEY, 2018). Normalmente os leques estão associados a bacias hidrográficas com grande amplitude altimétrica que fluem para amplas planícies, na qual a mudança nas condições do canal (confinado para não confinado) resulta na divergência do fluxo de modo concomitante à redução na velocidade média do fluxo em função das baixas declividades (CHARLTON, 2007).

Ressalta-se, conforme Vilas Boas et al. (1985), que embora os depósitos de leques aluviais sejam mais frequentes em áreas de clima árido ou semiárido, também ocorrem em regiões com atuação de clima úmido - tal como consta no estado do Paraná. Conceitualmente, Suguio (2003) cita que embora comumente cones e leques aluviais sejam tratados como sinônimo, considera-se, como diferenciação, que os cones possuem declividades superiores $\left(>5^{\circ}\right)$ aos leques $(<$ $\left.5^{\circ}\right)$.

A assinatura geomorfométrica, portanto, tem relação com variáveis afins à morfologia, abarcando aspectos denudacionais e agradacionais (erosão, transporte e deposição) do contexto mais amplo - tal como a bacia hidrográfica. Nesse sentido, a modelagem de leques aluviais, potencialmente tratadas no campo da geomorfometria específica, pode ser realizada a partir de parâmetros quantitativos de um MDT apoiado em questões semânticas da análise digital do relevo (DEHN et al., 2001; SMITH e MARK, 2003) numa perspectiva orientada a objeto (BISHOP et al., 2012).

Considerando algumas propostas prévias de modelagem, Hashimoto et al. (2008) analisaram a morfometria de leques aluviais no Japão e América do Sul, correlacionando as variações de declividade às distinções nos processos sedimentares e nas diferenças climáticas atuantes. Mais recentemente, Norini et al. (2016) elaboraram um algoritmo projetado para a detecção semiautomatizada (na Terra e em Marte) de leques aluviais, conectados à rede de drenagem, a partir da análise de MDTs. A proposta foi amparada em três regras: i) os leques ocorrem em 
locais de transição topográfica, seguindo a área do canal, quando há a mudança dos vales confinados para a planície não confinada; ii) os leques possuem forma cônica de declividade relativamente alta; iii) $A$ declividade da superfície cônica do leque aluvial é definida pela diferença de elevação e pela distância entre o ponto mais alto e mais baixo.

Outra proposta para mapeamento de leques aluviais foi apresentada por Pipaud e Lehmkuhl (2017), com um método supervisionado para delimitação a partir do MDE SRTM e com uso de uma máquina de vetor de suporte para a classificação. Nesse estudo, foram utilizados os atributos geomorfométricos declividade, curvatura, aspecto (orientação das vertentes), White Top Hat (WTH) e Black Top Hat (BTH). Destacam-se, ainda, os trabalhos de Hashemi et al. (2018), que quantificaram atributos morfométricos para 68 leques aluviais no Irã como auxílio à interpretação morfotectônica; Kain et al. (2018), que analisaram parâmetros morfométricos da bacia hidrográfica e dos leques aluviais numa região da Austrália; e Walk et al. (2019), que correlacionaram parâmetros morfométricos (calculados a partir de um modelo digital do TanDEM-X) com parâmetros geológicos e climáticos no deserto do Atacama.

Nesse sentido, este trabalho apresenta um novo método para mapeamento de leques aluviais com uso exclusivo da geomorfometria, numa classificação orientada a objeto. Os parâmetros foram definidos com base em atributos geomorfométricos derivados de MDT, cuja aplicação abrangeu todo o estado do Paraná (Brasil). A identificação dos leques aluviais foi correlacionada, num segundo momento, às interpretações sobre a evolução geomorfológica regional.

\section{MATERIAIS E MÉTODOS}

\section{Modelo Digital do Terreno e cálculo dos atributos geomorfométricos}

O modelo digital do terreno (MDT) utilizado possui resolução espacial de 20 metros e foi interpolado pelo método Topogrid (Hutchinson, 1989), contemplando pontos cotados, curvas de nível e hidrografia de cartas topográficas na escala 1:25.000 (Planície Litorânea e Serra do Mar) e 1:50.000 (restante do estado do Paraná). A matriz final do MDT, para toda a área de estudo, resultou numa grade de $33193 \times 23232$ células. A escolha do método Topogrid se deve ao algoritmo enforcement aplicado na drenagem, que confere feições escavadas no modelo resultante e com consistência hidrológica - essencial à modelagem proposta. 
A partir do MDT foram calculados cinco atributos geomorfométricos, utilizados posteriormente na classificação: área de contribuição, declividade (cálculo célula a célula), amplitude altimétrica, declividade média e amplitude da declividade média (cálculo zonal, por objetos). Os procedimentos operacionais foram realizados pelos softwares ArcGIS 10.1 e QGIS 3.4 .8 (com as ferramentas do software SAGA inclusas).

A área de contribuição foi quantificada pelo método proposto por Tarboton (1997), com o algoritmo D-Infinito processado pelo software SAGA (Flow Accumulation). Após indicação das direções, o fluxo acumulado é quantificado pela soma das células à montante, ou seja, pela contribuição acumulada do entorno mais elevado. Considera-se, portanto, que o fluxo de cada uma das células drena para algum de seus vizinhos, tendo esse valor somado ao seu. Por fim, a área de contribuição é obtida pela multiplicação da área de cada célula do MDT (neste caso, $400 \mathrm{~m}^{2}$, já que a resolução espacial é de $20 \mathrm{~m}$ ) pelo valor do fluxo acumulado (figura $1)$.

Figura 01 - Método D-Infinito para determinação da área de contribuição

\begin{tabular}{|c|c|c|c|c|c|c|c|c|c|c|c|c|c|c|c|c|c|c|c|}
\hline \multicolumn{5}{|c|}{$\begin{array}{c}\text { MDT (Altimetria) } \\
\text { (célula } 20 \mathrm{~m} \times 20 \mathrm{~m} \text { ) }\end{array}$} & \multicolumn{5}{|c|}{$\begin{array}{l}\text { Direção de fluxo } \\
\text { (D-Infinito) }\end{array}$} & \multicolumn{5}{|c|}{$\begin{array}{c}\text { Fluxo acumulado } \\
\text { (proporção de células) }\end{array}$} & \multicolumn{5}{|c|}{$\begin{array}{c}\text { Área de } \\
\text { contribuição }\left(\mathrm{m}^{2}\right)\end{array}$} \\
\hline 334 & 332 & 329 & 326 & 322 & 5.5 & 5.5 & 5.4 & 5.3 & 5.2 & 1 & 1 & 1 & 1 & 1 & 400 & 400 & 400 & 400 & 400 \\
\hline 333 & 329 & 324 & 320 & 316 & 5.9 & 5.8 & 5.5 & 5.5 & 5.2 & 1 & 2.5 & 3.1 & 2.2 & 2.1 & 400 & 1007 & 71221 & 861 & 851 \\
\hline 332 & 328 & 321 & 315 & 310 & 6.1 & 6.1 & 5.7 & 5.5 & 5.3 & 1 & 2.3 & 4.2 & 5.4 & 4 & 400 & 914 & 1693 & 2164 & 1589 \\
\hline 331 & 327 & 320 & 311 & 304 & 6.3 & 6.3 & 6.2 & 6 & 5.7 & 1 & 2.2 & 3.7 & 7.2 & 12.2 & 400 & 863 & 1492 & 2861 & 4886 \\
\hline 331 & 327 & 319 & 310 & 302 & 0 & 0 & 0 & 0 & 0 & 1 & 2 & 3.1 & 4.6 & 7.9 & 400 & 815 & 1247 & 1828 & 3176 \\
\hline
\end{tabular}

A declividade (slope), que mensura a inclinação da superfície, foi calculada a partir das variáveis direcionais de Horn (1981) com uma janela móvel 3x3 células (local). Os atributos geomorfométricos com cálculo zonal supracitados foram computados pela ferramenta Zonal Statistics no software ArcGIS 10.1, considerando os segmentos lineares definidos a partir da área de contribuição, descritos adiante.

\section{Parâmetros de modelagem morfocronológica}

A parametrização dos leques aluviais se pautou, inicialmente, pela abstração conceitual e ontológica acerca do objeto e da sua ocorrência na paisagem. A modelagem buscou traduzir, quantitativamente, características qualitativas intrínsecas à constituição da forma. Em aspectos teóricos, trata-se de uma transição 
da geomorfometria geral para a específica, pautada por uma classificação orientada a objeto que objetivou definir uma assinatura geomorfométrica - e que, portanto, possa ser replicada para outras áreas.

Considerando que leques aluviais, conforme descrito anteriormente, são feições de gênese fluvial, foi considerada a área de contribuição como parâmetro descritivo; visto que estão localizados em porções com quebras abruptas de relevo, incluiu-se a declividade; considerando que dependem das relações de energia no processo de erosão e deposição, inseriu-se a amplitude altimétrica.

Assim, os leques aluviais foram considerados como pontos planos localizados na interseção de segmentos lineares, definidos pela área de contribuição, que possuem grande amplitude altimétrica e de declividade. A proposta (figuras 2, 3 e 4) contém cinco etapas: i) definição dos segmentos lineares a partir da área de contribuição (> 1 km²); ii) atribuição de pontos na interseção dos segmentos (ou seja, pontos de confluência hídrica) com declividade local inferior a 8\%; iii) cálculo da amplitude altimétrica e declividade média de cada segmento; iv) atribuição da amplitude altimétrica para o segmento que possui a maior declividade média; v) determinação da amplitude da declividade média (segmento com a maior declividade média subtraído pelo segmento com a menor declividade média).

Dessa forma, foram considerados leques aluviais os pontos de confluência hídrica com declividade menor que $8 \%$, com amplitude altimétrica maior que $60 \mathrm{~m}$ e amplitude da declividade média dos segmentos maior que $8 \%$.

Por fim, os leques foram classificados em três níveis, segmentados pela amplitude altimétrica do segmento de maior declividade média: pequenos ( $>60 \mathrm{~m}$ e $<100 \mathrm{~m}$ ), intermediários (> $100 \mathrm{~m} \mathrm{e}<200 \mathrm{~m}$ ) e grandes (> $200 \mathrm{~m}$ ). 
Figura 02 - Regras classificatórias para identificação de leques aluviais

Obtenção dos segmentos lineares
Não

Figura 03 - Exemplo de parametrização de leques aluviais em área de escarpa

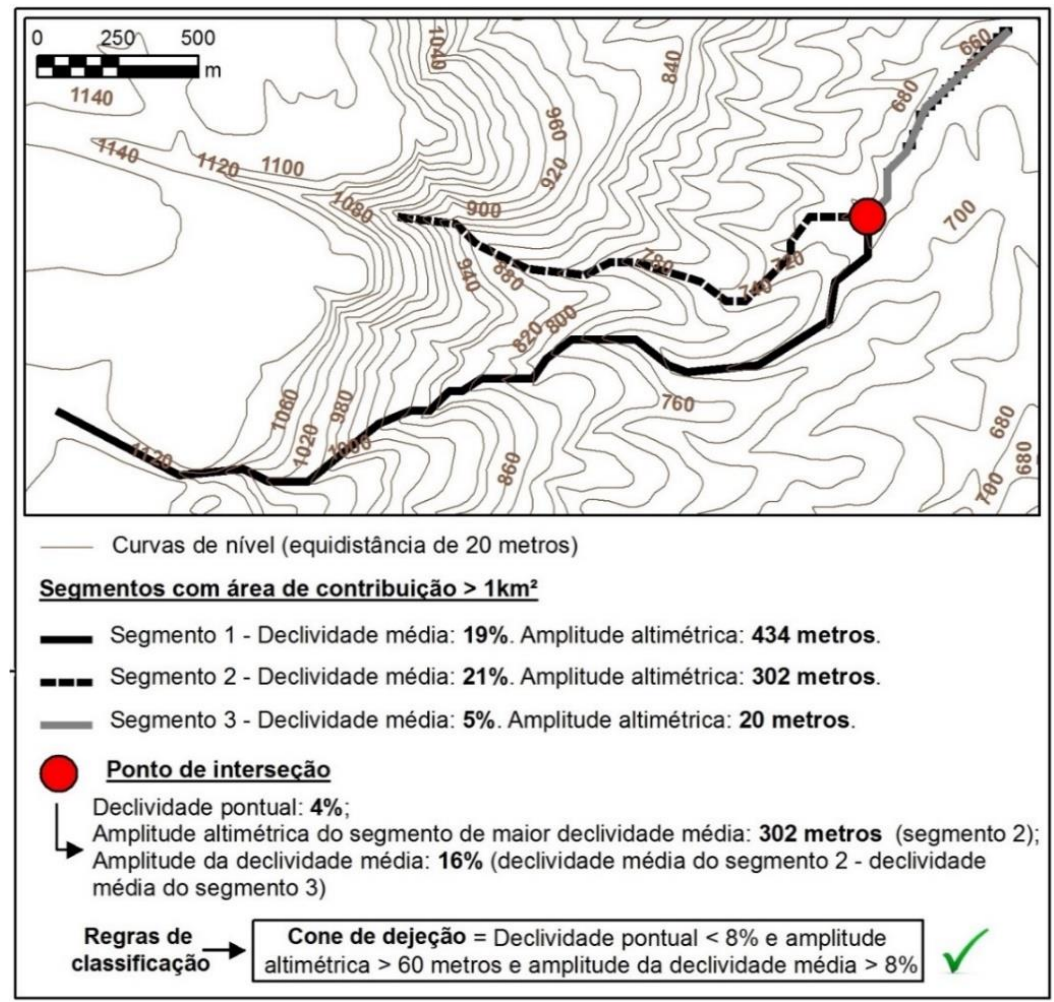


Figura 04 - Exemplo de parametrização de leques aluviais em área serrana

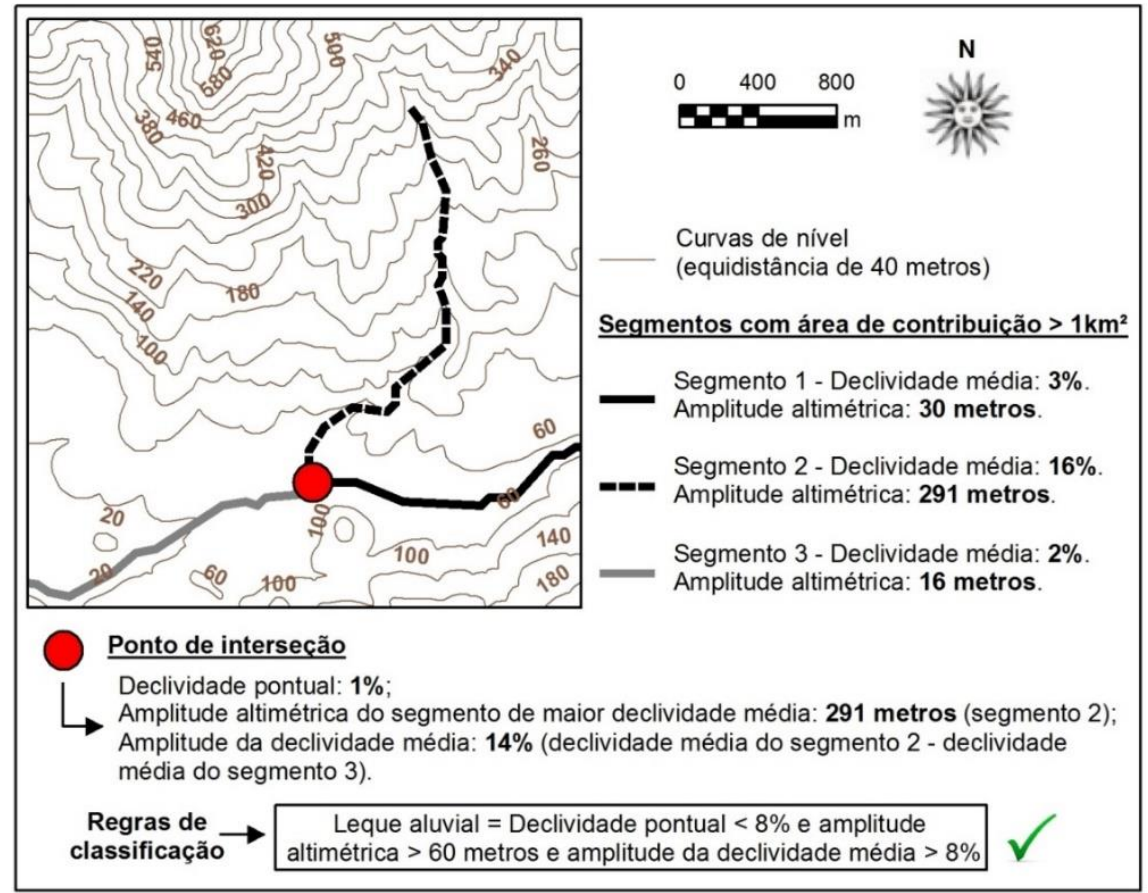

\section{RESULTADOS E DISCUSSÃO}

No estado do Paraná, conforme os parâmetros estabelecidos, foram mapeados 521 leques aluviais (figura 5). As análises dos resultados buscaram conciliar as etapas de campo (observações in loco) com mapeamentos ou interpretações prévias publicadas que tratam da evolução e dinâmica geomorfológica. Considerando, inicialmente, uma abordagem regional e uma análise abrangente, os resultados condizem com as características das grandes unidades geomorfológicas da área de estudo: Planície Litorânea, Serra do Mar, Primeiro, Segundo e Terceiro Planalto (MAACK, 1981; SANTOS et al., 2006).

As áreas mais dissecadas foram as que tiveram maior concentração de leques identificados. Em contrapartida, porções de relevo plano ou suave ondulado não registraram tais feições. A divisão entre os tamanhos de leques aluviais também evidenciou correlação com a geomorfologia regional (figura 5), uma vez que os grandes leques tenham sido mapeados, sobretudo, nos sopés de montanhas da região serrana, nos fronts de escarpas e nas demais áreas onde há destaque para a erosão diferencial - seja pelo controle litológico, seja pelos efeitos de nível de base das grandes bacias hidrográficas.

Os maiores leques aluviais modelados ocorrem nas adjacências da Serra do Mar (figura 5). Os leques circundam a região serrana na transição com o Primeiro Planalto e, em maior número, com a Planície Litorânea, já que o desnível altimétrico 
das vertentes voltadas para a face leste é maior, com valores superiores a $1500 \mathrm{~m}$, enquanto que para oeste o gradiente máximo é de $1000 \mathrm{~m}$. Os leques mapeados nos sopés da Serra do Mar evidenciam os processos morfodinâmicos e as relações degradacionais e agradacionais que vinculam eventos recentes com a própria conformação da Planície Litorânea e o recuo erosivo da escarpa serrana.

Figura 05 - Mapeamento de leques aluviais no estado do Paraná

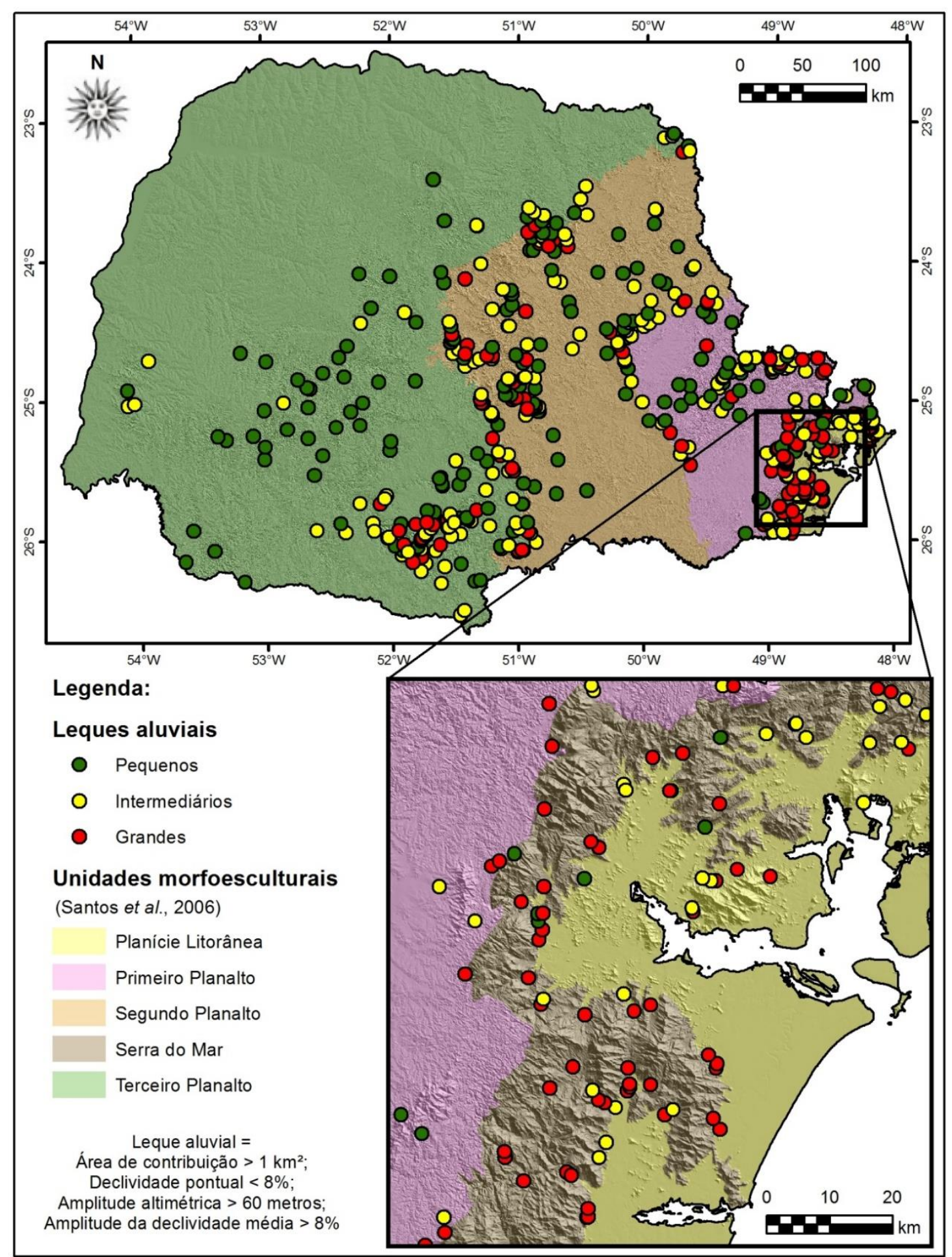


Conceitualmente, os resultados da modelagem foram concordantes às características ontológicas das feições, isto é, foram mapeadas conforme os preceitos teóricos da morfologia. A Serra do Mar possui alta densidade de drenagem, disponibilidade de material a montante para erosão e transporte (associado ao clima e ao efeito orográfico) e rupturas de declive nos terços inferiores das vertentes, definindo os ambientes deposicionais. Muitas planícies de inundação localizadas no sopé da Serra do Mar estão associadas a sistemas de cones de dejeção de detritos (figuras 6 e 7).

O mapa geomorfológico da Folha SG.22 Curitiba (COSTA et al., 2005) do Projeto RADAMBRASIL (BARBOSA et al., 1984), cartografou todas as planícies confinadas nos grandes vales da Serra do Mar como "Planícies AlúvioColuvionares", na categoria "Rampas de colúvio". Foram caracterizadas como modelado de acumulação, em áreas planas ou embaciadas, resultante da convergência de leques coluviais, cones de dejeção ou da concentração de depósitos de enxurradas nas partes terminais da rampa de pedimentos. O mapa resultante do zoneamento do litoral paranaense, realizado pelo IPARDES (1989), classifica essas porções como "Áreas coluviais", e o mapa geológico do estado do Paraná (MINEROPAR, 2001) como "Aluviões recentes".

$E$, de fato, o presente mapeamento indicou que $20 \%$ dos leques aluviais modelados no estado do Paraná na categoria de "grandes" (ou seja, com amplitude superior a $200 \mathrm{~m}$ na regra de classificação), encontram-se dentro das unidades referente às rampas de colúvio do mapeamento do RADAMBRASIL. Complementarmente, o sopé da Serra do Mar também foi a área de maior densidade de leques aluviais mapeados. Nesse caso, a concentração de feições pontuais características validam as unidades homogêneas delimitadas por mapeamentos de escala mais generalizada.

Numa escala têmporo-espacial maior, a análise individualizada dos leques trouxe importantes contribuições para a compreensão da morfogênese e morfodinâmica local. A Serra da Prata (bacia do rio Jacareí), por exemplo, registrou um evento de grande magnitude de movimentos de massa no ano de 2011 (figura 6). Os resultados obtidos pela modelagem coincidem com a interpretação realizada por Silveira et al. (2014) no mesmo recorte. Segundo os autores, referindo-se à planície, "o material mais grosso depositou-se na desembocadura dos canais na forma de cones de detritos, enquanto que o material lenhoso e os sedimentos finos atingiram grandes extensões na planície na forma de corridas de lama" (p. 4). 
Figura 06 - Leque aluvial na bacia hidrográfica do rio Jacareí, Serra da Prata

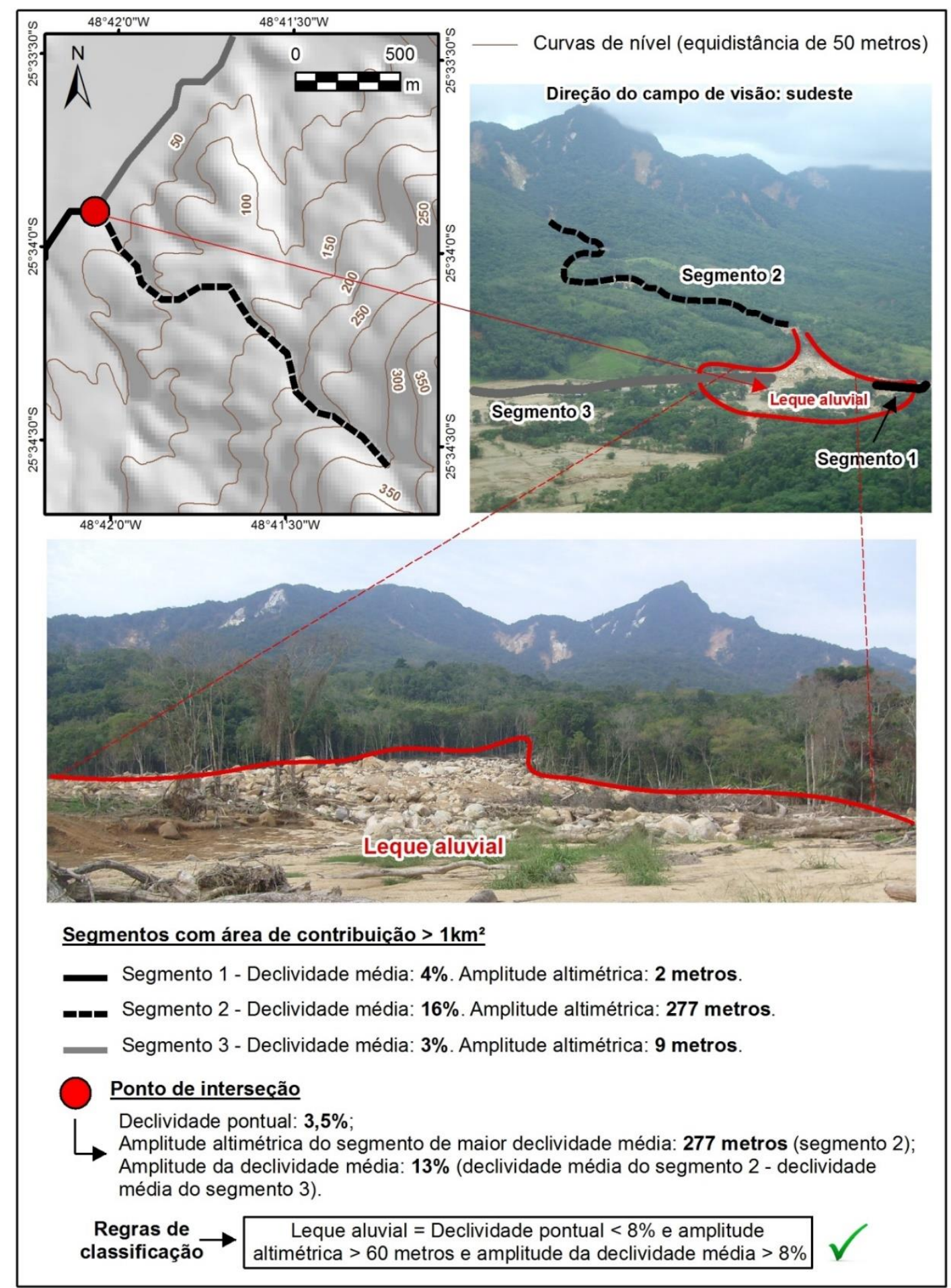

O evento expôs o leque aluvial, com a remoção da cobertura vegetal e remobilização de material alúvio-coluvionar, além do aporte sedimentar decorrente dos movimentos de massa. Esse exemplo denota uma perspectiva evolutiva do relevo: escorregamentos translacionais nos terços superiores das vertentes, corridas de detritos pelos vales fechados nos terços médios e deposição no terço inferior em função da ruptura de declive e diminuição abrupta da capacidade de transporte. $O$ 
resultado é o espraiamento do material em forma cônica. No âmbito da atribuição qualitativa, esse leque aluvial (figura 6) foi classificado como grande, já que a amplitude altimétrica do segmento de maior declividade média (ou seja, a área fonte, enfatizada pela fotografia: o segmento 2) foi de 277 metros.

Devido à reordenação natural da paisagem, em poucos anos as cicatrizes dos eventos morfodinâmicos são ocultadas pela rápida recuperação da vegetação. $A$ morfologia, todavia, pode testemunhar eventos pretéritos. No município de Guaratuba, no contato entre Serra do Mar e Planície Litorânea, observa-se feição característica de leques de ambientes agradacionais (figura 7), ainda que sem evidências da ocorrência de grandes eventos erosivos recentes, associada a pronunciadas planícies de inundação. Nesse caso, a amplitude altimétrica foi de 192 $\mathrm{m}$, enquadrando-se na categoria definida como leques aluviais intermediários.

Deve-se considerar, nesse recorte, uma especificidade da proposta metodológica apresentada. O ponto de interseção está localizado a $500 \mathrm{~m}$ da quebra de declive que marca o início da Planície Litorânea, pois os leques foram mapeados na confluência hídrica (a foz do segmento 2). Na prática, isso significa que esse leque aluvial possui maior extensão longitudinal e, em consequência, menor convexidade, sendo uma feição possivelmente mais antiga e, portanto, mais retrabalhada. Em suma, destaca-se que os pontos com a indicação dos leques não correspondem necessariamente ao centroide da feição, podendo ser uma localização aproximada.

Quanto aos leques aluviais do Primeiro Planalto, ao todo foram mapeados 104 feições, que representam 20\% do total identificado no estado do Paraná. Desses 104 leques, 24,1\% foram categorizados como grandes, 43,3\% como médios e $32,6 \%$ como pequenos. Os leques de maior expressividade (com amplitude altimétrica superior a $200 \mathrm{~m}$ ) foram modelados corretamente nos contatos com as elevações da Serra do Mar, a leste, e com a escarpa na transição para o Segundo Planalto, a oeste (figura 3 e figura 8), que evidencia o recuo erosivo dessa feição estrutural e expõe os leques aluviais como testemunho de processos agradacionais. 
Figura 07 - Leque aluvial no contato entre Serra do Mar e Planície Litorânea, município de Guaratuba

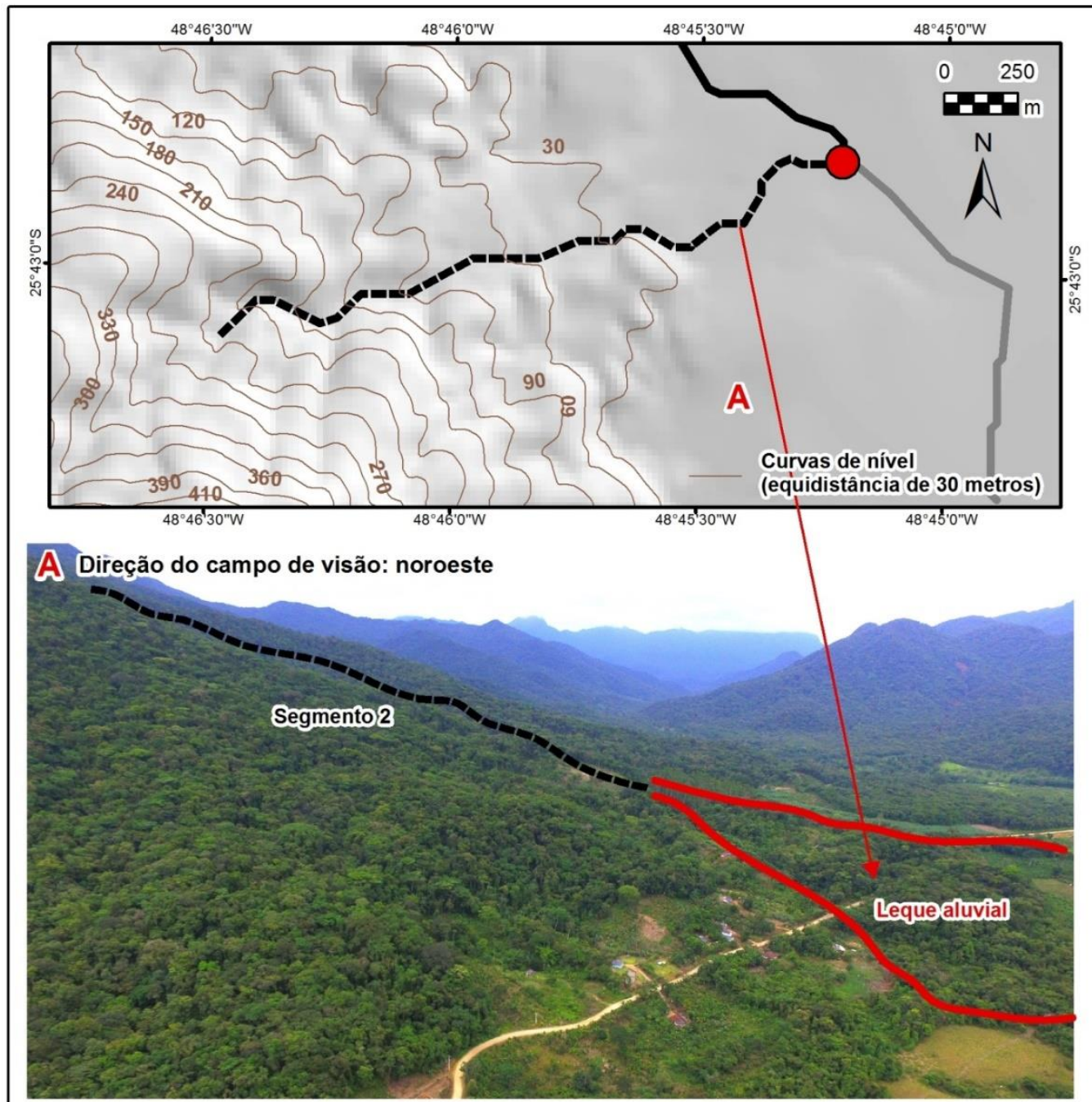

Segmentos com área de contribuição $>1 \mathrm{~km}^{2}$

- Segmento 1 - Declividade média: 1,5\%. Amplitude altimétrica: 5 metros.

- Segmento 2 - Declividade média: 10\%. Amplitude altimétrica: 192 metros.

Segmento 3 - Declividade média: 0,3\%. Amplitude altimétrica: 3 metros.

\section{Ponto de interseção}

Declividade pontual: $\mathbf{0 , 5 \%}$;

Amplitude altimétrica do segmento de maior declividade média: 192 metros (segmento 2); Amplitude da declividade média: $\mathbf{9 , 7} \%$ (declividade média do segmento 2 - declividade média do segmento 3 ).

\begin{tabular}{|c|c|}
\hline $\begin{array}{l}\text { e } \\
\text { ão }\end{array} \rightarrow$ & $\begin{array}{l}\text { e aluvial }=\text { Declividade pontual }<8 \% \text { e amplitude } \\
>60 \text { metros e amplitude da declividade média }>8 \%\end{array}$ \\
\hline
\end{tabular}


Figura 08 - Leques aluviais na escarpa de Jaguariaíva (Vale do Codó)

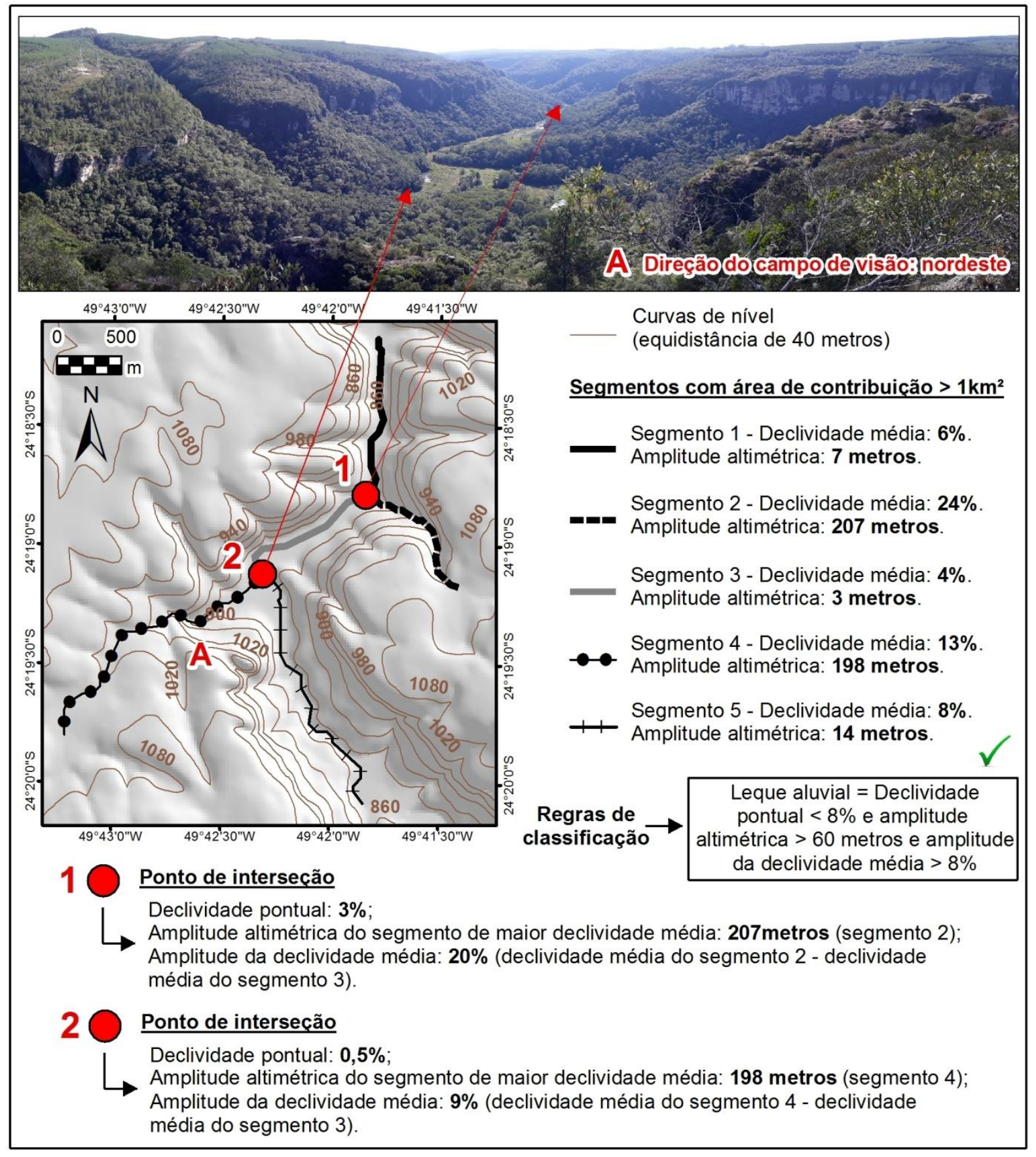

Os demais leques foram modelados integralmente na bacia hidrográfica do rio Ribeira, que contempla o norte do Primeiro Planalto. Enquanto o sul do Primeiro Planalto é drenado pela bacia do rio Iguaçu, que segue a oeste, a bacia do Ribeira segue a leste e tem maior poder erosivo devido à proximidade com o nível de base geral (relação entre extensão e desnível altimétrico), além da própria complexidade litológica e os efeitos da erosão diferencial. Consequentemente, a porção norte é bastante dissecada e contabiliza muitos leques aluviais. Já o sul, que inclui a bacia sedimentar de Curitiba, não possui leques aluviais de expressividade regional. 
$\mathrm{Na}$ transição para o Segundo Planalto, que marca o início da bacia sedimentar do Paraná, observa-se no município de Jaguariaíva a presença de leques aluviais identificados numa reentrância erosiva da escarpa com vales em "V" (figura 8). Apesar das semelhanças morfométricas, o leque 1 (com amplitude de 207 metros) foi classificado na categoria de grande e o leque 2 (amplitude de $198 \mathrm{~m}$ ) de intermediário. O segmento 3 caracteriza uma planície de inundação com aproximadamente $0,15 \mathrm{~km}^{2}$, cuja extensão perpendicular não ultrapassa $200 \mathrm{~m}$, sendo o ambiente agradacional para ambos os leques. O contraste com os leques aluviais serranos reforça que a parametrização estabelecida obteve resultados satisfatórios tanto em extensas planícies (como a litorânea) quanto em casos particulares como esse apresentado. A assinatura geomorfométrica, portanto, manteve-se representativa em distintos contextos geomorfológicos.

Próximo às escarpas, comumente os leques aluviais são intercalados com depósitos coluvionares. Os rios promovem as incisões verticais, que alargam os vales e potencializam os processos denudacionais, ao mesmo tempo em que a erosão lateral avança pelo solapamento da base. Na transição entre Primeiro e Segundo Planalto, o Arenito Furnas, mais resistente à erosão devido à presença de caulinita (MELO, 2013), sustenta a escarpa.

Próximo da transição entre Segundo e Terceiro Planalto, outro exemplo da influência do controle litológico na formação de leques aluviais consta na região de Prudentópolis, notabilizada por concentrar muitas cachoeiras, na qual a presença de rochas magmáticas intercaladas às rochas sedimentares promove variações no relevo local. $\mathrm{Na}$ Serra da Esperança, há o contato entre rochas vulcanosedimentares, com feições testemunhas do recuo erosivo da escarpa basáltica. Além dos diques orientados a noroeste, as soleiras de diabásio - espraiadas horizontalmente - sustentam elevações de modo contínuo, formando "pequenos planaltos" com extensão que pode chegar à dezena de quilômetro e com muitos leques aluviais associados. Isso ocorre, por exemplo, no Salto São João (figura 9), onde há uma soleira de diabásio intraposta verticalmente no arenito da Formação Teresina, do Grupo Passa Dois (MINEROPAR, 2001), e que circunda, horizontalmente, uma porção do vale do rio Ivaí e alguns afluentes num segmento sucessivo de $120 \mathrm{~km}$, contabilizando as duas margens, com 16 leques aluviais nas adjacências.

A evolução morfológica dessa área (figura 9), com a presença de vertentes escarpadas e quedas d'água, pode ser explicada pelo solapamento da base, a partir 
das incisões fluviais, seguido da queda dos blocos de diabásio por gravidade. Como consequência, há o processo de erosão remontante. Ainda que o topo seja coberto novamente pelo arenito da Formação Teresina, a camada ígnea poucos metros abaixo controla o nível altimétrico e a declividade local.

Figura 09 - Leques aluviais na região de Prudentópolis (Segundo Planalto)

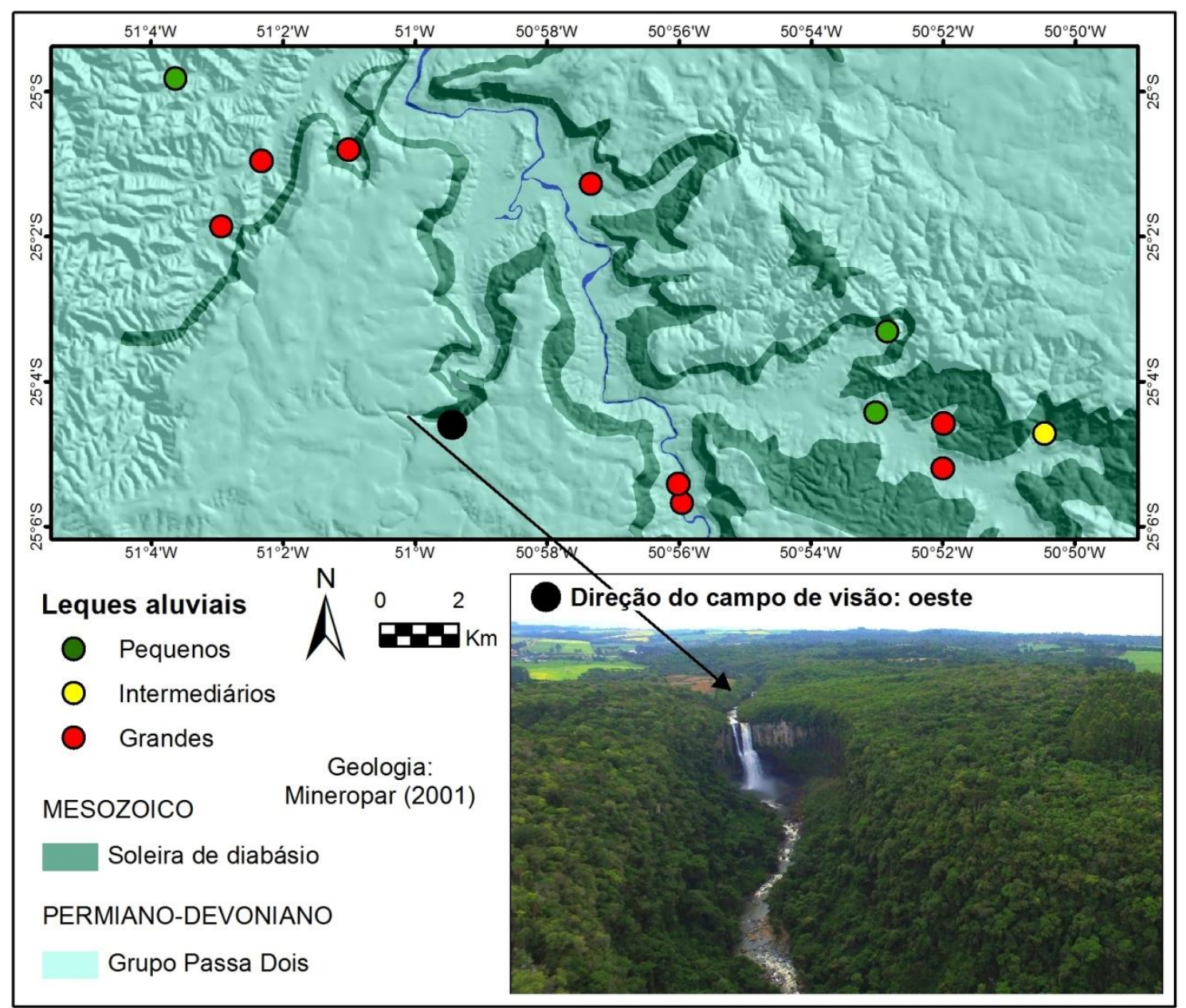

No Terceiro Planalto, os maiores leques aluviais foram mapeados na porção sul, na subunidade morfoescultural denominada Planalto do Foz de Areia pelo mapa geomorfológico do estado do Paraná (SANTOS et al., 2006; OKA-FIORI et al., 2006). Trata-se das áreas dissecadas pelo rio Iguaçu. A região noroeste não teve leques aluviais identificados, considerando os parâmetros estabelecidos, já que a área possui relevo predominantemente suave ondulado. Reforça-se, todavia, que se os parâmetros da modelagem incluírem valores menores dos atributos geomorfométricos, leques menores podem ser mapeados.

$O$ fator que explica a existência de maiores leques aluviais na porção sul do Terceiro Planalto remonta à morfogênese regional. Há diferenças importantes nas características dos derrames que alteram a estrutura interna do material ígneo e, por 
conseguinte, alteram as estruturas superficiais, os níveis de erosão e as formas de relevo agradacionais, como os leques aluviais. Os derrames que recobrem 0 Terceiro Planalto constituem a Formação Serra Geral, caracterizada por uma sucessão de derrames com uma espessura máxima de cerca de 1700 metros (WAICHEL et al., 2006).

Ainda que $77 \%$ do Terceiro Planalto $(50 \%$ do estado do Paraná) seja recoberto pela Formação Serra Geral, com predominância de basaltos (MINEROPAR, 2001), o mencionado evento vulcânico possui fases e particularidades que tornam seu arranjo bastante heterogêneo: características das erupções hidrovulcânicas e dos eventos explosivos em centros eruptivos, depósitos de quedas das cinzas vulcânicas, interdigitação de produtos (como derrames, vulcanoclastos e piroclastos) e a própria sucessão dos depósitos vulcanoclásticos. Essas características derivam um relevo dissecado em algumas porções, que viabilizam a formação dos leques aluviais.

$\mathrm{Na}$ região noroeste do estado do Paraná, por sua vez, sobreposto aos derrames basálticos, consta uma cobertura sedimentar arenosa (dunas eólicas desérticas) depositada em ambiente árido no final do Cretáceo, correspondente ao Grupo Bauru, com predomínio da Formação Caiuá, conforme o mapeamento geológico publicado pela Mineropar (2001). Tal cobertura sedimentar condiciona um relevo com colinas suave onduladas, de baixa declividade, que limitam a ocorrência de leques aluviais com extensão significativa.

Quanto aos critérios empregados na modelagem, reforça-se que os valores escolhidos devem ser vinculados aos objetivos da representação - ou seja, trata-se de uma questão escalar. No presente trabalho, em função da extensão da área de estudo e da ênfase na abordagem regional, os parâmetros foram definidos para indicar apenas as feições de maior proeminência. Para estudos mais detalhados, a mudança nos valores pode representar os leques aluviais menores. A lógica de classificação, entretanto, permanece a mesma.

\section{CONCLUSÃO}

Os leques aluviais foram modelados a partir de uma proposição metodológica cuja concepção reflete, de modo didático, o raciocínio envolvido numa classificação orientada a objeto no âmbito da geomorfometria específica. Por ser uma proposição metodológica, destaca-se que os parâmetros utilizados podem ser ajustados aos objetivos pretendidos e às escalas predefinidas para o mapeamento. De modo geral, 
seja pelos leques aluviais reconhecidos in loco, seja pela interpretação visual ou por meio de reconhecimento na literatura, o método obteve êxito na identificação desse objeto morfográfico.

O mapeamento considerou a amplitude altimétrica e declividade média de segmentos de drenagem (definidos pela área de contribuição) e a declividade local nos pontos de inserseção (confluência) entre esses segmentos. Assim, pontos localizados em áreas suavemente onduladas, com grande desnível altimétrico e quebra de declive dos rios, foram modelados como leques aluviais.

A assinatura geomorfométrica foi representativa em distintos contextos geomorfológicos, considerando a variedade de relevo do estado do Paraná, o que ressalta sua aplicabilidade. A limitação detectada da proposta condiz à atribuição dos leques somente nos pontos de confluência hídrica, pois isso pode excluir os leques formados por rios que, ao desaguarem numa porção mais plana, com quebra de declive, não tenham afluentes. Além disso, como os leques são mapeados automaticamente nas interseções, alguns pontos estão distantes dos sopés das vertentes - onde os leques aluviais, de fato, estão localizados.

Salienta-se que o rigor metodológico em todas as etapas da modelagem é imprescindível para assegurar resultados satisfatórios. Recomenda-se o uso do método Topogrid para interpolação do MDT, pois o algoritmo favorece a extração das feições hidrológicas indispensáveis à modelagem dos leques aluviais.

\section{REFERÊNCIAS}

ALMEIDA, F. F. M.; CARNEIRO, C. D. R. Origem e evolução da Serra do Mar. Revista Brasileira de Geociências, n. 28, v. 2, p. 135-150, 1998.

BARBOSA, G. V.; SILVA, T. C.; NATALI FILHO, T.; DEL'ARCO, D. M.; COSTA, R. C. R. Evolução da metodologia para mapeamento geomorfológico do Projeto Radambrasil. Boletim Técnico, Série Geomorfologia. Salvador n. 1, 187 p., 1984.

BISHOP, M. P.; JAMES, A.; SHRODER, J. F.; WALSH, S. J. Geospatial technologies and geomorphological mapping: concepts, issues and research directions. Geomorphology 137, p. 5-26, 2012.

BOLONGARO-CREVENNA, A.; TORRES-RODRÍGUEZ, V.; SORANI, V.; FRAME, D.; ORTIZ, M. A. Geomorphometric analysis for characterizing landforms in Morelos State, Mexico. Geomorphology 67 (3-4), p. 407-422, 2005.

CHARLTON, R. Fundamentals of Fluvial Geomorphology. London: Routledge, 2007.

COSTA, R. C. R.; BUSS, M. D.; ROSA, R. O. Geomorfologia. In: Levantamento de Recursos Naturais, Volume 35: folha SG.22 Curitiba, parte da folha SG.21 Asunción e folha 
SG.23 Iguape (Relatório técnico do Projeto RADAMBRASIL). Org.: Instituto Brasileiro de Geografia e Estatística (IBGE), Rio de Janeiro, 2005.

DEHN, M.; GARTNER, H.; DIKAU, R. Principles of semantic modeling of landform structures. Computers and Geosciences, 27, p. 1005-1010, 2001.

EVANS, I. S. General geomorphometry, derivatives of altitude, and descriptive statistics. In: CHORLEY, R. J. (Ed.). Spatial analysis in geomorphology. London: Harper \& Row, Publishers, 1972.

EVANS, I. S. Geomorphometry and landform mapping: What is a landform? Geomorphology 137 (2012) 94-106, 2012.

HARVEY, A. Alluvial Fans. Reference Module in Earth Systems and Environmental Sciences, Elsevier, 2018.

HASHIMOTO, A.; OGUCHI, T.; HAYAKAWA, Y.; LIN, Z.; SAITO, K.; WASKLEWICZ, T. A. GIS analysis of depositional slope change at alluvial-fan toes in Japan and the American Southwest. Geomorphology, v. 100, p. 120-30, 2008.

HENGL, T.; REUTER, H. I. (eds.) Geomorphometry - Concepts, Software, Applications, Series Developments in Soil Science vol. 33, Amsterdam: Elsevier, pp. 3-30, 2009.

HORN, B. K. P. Hill shading and the reflectance map. Proceedings of the IEEE, n. 69, v.01, p. 14-47, 1981.

HUTCHINSON, M. F. A new procedure for gridding elevation and stream line data with automatic removal of spurious pits. Journal of Hydrology, 106, p. 211-272, 1989.

KAINA, C. L.; RIGBYB, E. H.; MAZENGARB, C. A combined morphometric, sedimentary, GIS and modelling analysis offlooding and debrisflow hazard on a composite alluvial fan, Caveside, Tasmania. Sedimentary Geology 364, p. 286-301, 2018.

LI, Z.; ZHU, Q.; GOLD, C. Digital Terrain Modeling: Principles and Methodology. Boca Raton: CRC Press, 2005.

MAACK, R. R. Geografia Física do Estado do Paraná. 2. ed. Curitiba: Ed. Olympio, 1981.

MELO, M.S. Perfurações de cupins e geomorfogênese em arenitos paleozoicos da região dos Campos Gerais do Paraná. Quaternary and Environmental Geosciences, v. 4, p. 2533, 2013.

MACMILLAN, R. A.; SHARY, P. A. Landform and landform elements in geomorphometry. In: HENGL, T.; REUTER, H. I. (eds.) Geomorphometry - Concepts, Software, Applications, Series Developments in Soil Science vol. 33, Amsterdam: Elsevier, pp. 227-254, 2009.

MINEROPAR - Minerais do Paraná S/A. Atlas geológico do estado do Paraná. 116 p. Curitiba, 2001.

NORINI, G.; ZULUAGA, M. C.; ORTIZ, I. J.; AQUINO, D. T.; LAGMAY, A. M. F. Delineation of alluvial fans from Digital Elevation Models with a GIS algorithm for the geomorphological mapping of the Earth and Mars. Geomorphology 273, p. 134-149, 2016.

OKA-FIORI, C.; SANTOS, L. J. C.; CANALI, N. E.; FIORI, A. P.; SILVEIRA, C. T.; BRISKI, S. J.; FELIPE, R. S.; SILVA, J. M. F.; ROSS, J. L. S. Atlas Geomorfológico do Estado do Paraná: escala base 1:250.000, modelos reduzidos 1:500.000. MINEROPAR; Universidade Federal do Paraná, Curitiba, 63 p., 2006. 
PIKE, R. J. Geomorphometry - diversity in quantitative surface analysis. Progress in Physical Geography 24 (1), 1-20, 2000.

PIKE, R. J. The geometric signature: quantifying landslide-terrain types from digital elevation models. Mathematical Geology 20, 491-511, 1988.

PIPAUD, I.; LEHMKUHL, F. Object-based delineation and classification of alluvial fans by application of mean-shift segmentation and support vector machines. Geomorphology 293, p. 178-200, 2017.

SANTOS, L. J. C.; OKA-FIORI, C.; CANALI, N. E.; FIORI, A. P.; SILVEIRA, C. T.; SILVA, J. M. F.; ROSS, J. L. S. Mapeamento geomorfológico do Estado do Paraná. Revista Brasileira de Geomorfologia, n. 2, p. 3-12, 2006.

SILVEIRA, C. T.; FIORI, A. P.; SCHILIPACK, P.; DIAS, S. M. Mapeamento preliminar da suscetibilidade natural a movimentos de massa da Serra do Mar Paranaense apoiado na análise digital do relevo. Revista Brasileira de Geomorfologia, v. 15, n. 1, p. 3-22, 2014.

SMITH, B.; MARK, D. M. Do mountains exist? Towards an ontology of landforms. Environment and Planning B: Planning and Design 30 (3), 411-427, 2003.

TARBOTON, D. G. A New Method for the Determination of Flow Directions and Contributing Areas in Grid Digital Elevation Models. Water Resources Research, 33(2): 309-319, 1997.

WAICHEL, B. L. Tipos de derrame e reconhecimento de estruturas nos basaltos da Formação Serra Geral - Terminologia e aspectos de campo. Pesquisas em Geociências (UFRGS), v. 33, p. 123-133, 2006b.

WALK, J.; STAUCH, G.; REYERS, M.; VÁSQUEZ, P.; SEPÚLVEDA, F. A.; BARTZ, M.; HOFFMEISTER, D.; BRÜCKNER, H.; LEHMKUHL, F. Gradients in climate, geology, and topography affecting coastal alluvial fan morphodynamics in hyperarid regions - The Atacama perspective. Global and Planetary Change, 2019.

WILSON, J. P. Digital terrain modelling. Geomorphology, 137, p.107-121, 2012.

WILSON, J. P.; GALLANT, J. C. (eds.). Terrain analysis: principles and applications. New York: John Wiley \& Sons, p.1-27, 2000.

\section{NOTAS DE AUTOR}

\section{CONTRIBUIÇÃO DE AUTORIA}

Ricardo Michael Pinheiro Silveira - Concepção; Coleta de dados; Análise de dados; Elaboração do manuscrito; Participação ativa da discussão dos resultados.

Claudinei Taborda da Silveira - Coleta de dados; Análise de dados; Participação ativa da discussão dos resultados; Revisão e aprovação da versão final do trabalho.

\section{FINANCIAMENTO}

Os autores agradecem à Coordenação de Aperfeiçoamento de Pessoal de Nível Superior (CAPES) pelas bolsas de fomento de nível doutorado e pós-doutorado, concedida por meio do Programa de Pós-Graduação em Geografia da Universidade Federal do Paraná (PPGGEO-UFPR), e ao Conselho Nacional de Desenvolvimento Científico e Tecnológico (CNPq), pela disponibilização dos recursos financeiros que contribuíram com a realização do trabalho e os levantamentos de campo, por meio dos projetos "Mapeamento Geomorfológico do Estado do Paraná apoiado em análise digital do relevo, Processo no 456244/2014-0, Apoio a Projetos de Pesquisa / MCTI/CNPQ/Universal 14/2014 - Faixa A" e "Desenvolvimento metodológico e aplicações modelagem digital do terreno no mapeamento geomorfológico", Processo n 434343/2018-8, Apoio a Projetos de Pesquisa / MCTI/CNPQ/Universal 28/2018 - Faixa B. 
CONSENTIMENTO DE USO DE IMAGEM

Não se aplica.

APROVAÇÃO DE COMITÊ DE ÉTICA EM PESQUISA

Não se aplica.

\section{CONFLITO DE INTERESSES}

Não se aplica.

\section{LICENÇA DE USO}

Este artigo está licenciado sob a Licença Creative Commons CC-BY. Com essa licença você pode compartilhar, adaptar, criar para qualquer fim, desde que atribua a autoria da obra.

\section{HISTÓRICO}

Recebido em: 09-01-2020

Aprovado em: 13-05-2020 